\title{
Pseudo-heart Failure Due to a Large Hiatal Hernia
}

\author{
Ken Kawabe ${ }^{1,2}$, Norifumi Tsutsumi ${ }^{2,3}$ and Koji Ikejiri ${ }^{2,3}$
}

Key words: hiatal hernia, heart failure, cardiac compression, left atrium

(Intern Med 58: 3483-3484, 2019)

(DOI: 10.2169/internalmedicine.3167-19)

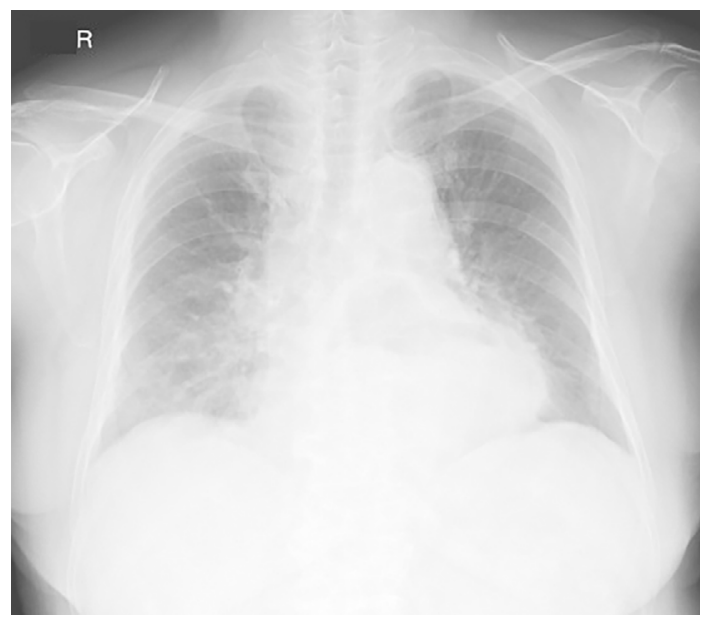

Picture 1.

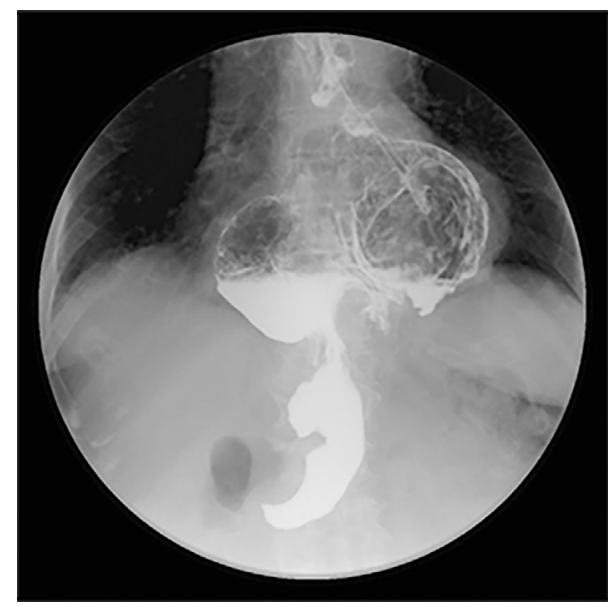

Picture 3.

An 83-year-old woman with diabetes mellitus presented with a 2-month history of shortness of breath and heartburn. A chest radiograph showed cardiac expansion and bilateral

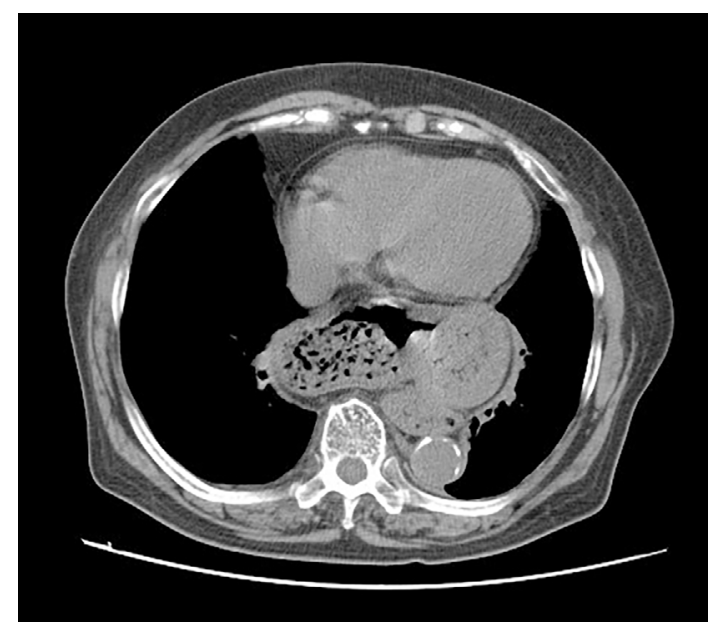

Picture 2.

hilar vascular shadow enhancement (Picture 1). An electrocardiogram revealed sinus rhythm, and an echocardiogram revealed preservation of the cardiac function. Initially, congestive heart failure was considered, but diuretics were not effective. A careful re-examination of the chest radiograph revealed an abnormal gas shadow inside the mediastinum. Additional computed tomography and contrast barium radiography revealed a large hiatal hernia $(\mathrm{HH})$ with most of the stomach escaping into the thoracic cavity (Picture 2, 3), resulting in mediastinal expansion due to cardiac compression by the HH. Enlarged HHs can compress the anatomically adjacent left atrium, resulting in dysfunction of the left atrium and causing heart failure-like symptoms (1). In the present case, surgical HH repair promptly improved the patient's clinical symptoms and chest radiograph abnormalities.

The authors state that they have no Conflict of Interest (COI).

\section{Acknowledgement}

We thank Angela Morben, DVM, ELS, for editing a draft of

${ }^{1}$ Department of Gastroenterology, National Hospital Organization Kyushu Medical Center, Japan, ${ }^{2}$ Clinical Research Institute, National Hospital Organization Kyushu Medical Center, Japan and ${ }^{3}$ Department of Surgery, National Hospital Organization Kyushu Medical Center, Japan Received: April 8, 2019; Accepted: June 12, 2019; Advance Publication by J-STAGE: July 22, 2019 Correspondence to Dr. Ken Kawabe, kawabe.ken.ef@mail.hosp.go.jp 
this manuscript.

\section{Reference}

1. Naoum C, Falk GL, Ng ACC, et al. Left atrial compression and the mechanism of exercise impairment in patients with a large hia- tal hernia. J Am Coll Cardiol 58: 1624-1634, 2011.

The Internal Medicine is an Open Access journal distributed under the Creative Commons Attribution-NonCommercial-NoDerivatives 4.0 International License. To view the details of this license, please visit (https://creativecommons.org/licenses/ by-nc-nd/4.0/).

\section{(C) 2019 The Japanese Society of Internal Medicine Intern Med 58: 3483-3484, 2019}

